\title{
Tres Temas de Etnología
}

\section{1 - Ideas básicas acerca de la cultura \\ 2-Bases para un estudio de integración regional 3-La "Cultura Emergente"}

POR LUIS E. VALCÁRCEL

\section{IDEAS BASICAS ACERCA DE IA CULTURA}

Siendo lo que entendemos por cultura una creación del hombre para el hombre, tiene que partirse de la idea fundamental acerca de la existencia humana, concebida ésta como un tránsito y por tanto como un período limitado en su duración. La existencia del hombre, de cada hombre, es el único supuesto verdadero para la edificación de todo el sistemá do la culiura. Esta temporalidad de la vida humana caracteriza todos los actos que tienen que realizarse en un tiempo $\mathrm{y}$ en un lugar dado. La existencia está, pues, limitada por el espacio y el tiempo, por la geografía y la historia. A pesar de esta concienció de la límitación, el hombre aspira a perennizarse, proyectóndose hacia atrás en la historia y hacia adelante en la religión y el mito. Desenvolviéndose la vida humana entre el nacimiento y la muerte, puede decirse que comlenza y termina en lo desconocido. Pero el hombre como ser físico está integrando la naturaleza y está sometido a leyes: vivir es subsistir. El organismo humano como todo otro organlsmo necesita tomar de su medio ambiente los elementos físicos esenciales para la existencia, como el alimento. Es, por lo tanto, base esencial la subsistencia. Esto importa que el hombre encuentre la posibilidad de dominar su medio físico, mediante su inteligencia y su acción. Primero conocer $y$ en seguida hacer. Así surgen lo que entendemos por ciencia y técnica. 
Es evidente que la naturaleza toma su desquite e influye, a su vez, sobre el hombre y sobre la cultura, determinando en clerta medida la orientación del grupo humano y muchas de sus coracterísticas. Prueba es de fllo la clasificación antigua y persistente de los pueblos en recolectores, pescadores y cazadores.

Aun dentro de un nivel superior aparecen influyendo los sistemas agrícolas e industriales que se basan en la realidad físico. del ambiente en que se desarrollan. Mas, el creciente poder del hombre anula en cierta medida los factores negativos de orden natural o los modifica en el sentido de hacerlos favorables. De todos modos, se tiene que reconocer límites infranqueables a la acción humana.

Lo esencial en el hombre es que pertenece a una especte zoológica cuyo signo es lo social. La idea del hombre implica la idea de la sociedad. Se vive con otros hombres y este sólo hecho determina una ineluctable condición de vida. La coexistencia humana es, pues, otro fundamentó de la existencia individual. La regulación de las relaciones entre los hombres ha determinado la creación de sistemas de convivencia como el derecho, la moral y la política. Pero esta coexistencia está ligada íntimamente a los imperativos de la subsistencia $y$, por consiguiente a las relaciones entre el hombre y la naturaleza. La lucha y la cooperación han sido y son las alternativas de este doble movimiento de acción y reacción entre los hombres y dé éstos con el mundo físico. Por otro lado, la "ciencia y lick lécnica han contibuido al dominio creciente de los recursos naturales. La combinación de subsistencia y coexistencta da como fruto la actividad denominada economía.

Gravitando en forma imperativa sobre el espíritu humano las demandas de lo desconocido que se relacionan esencialmente con los enigmas del nacimiento y de la muerte, el hombre ha respondido con la creación de un mundo sobrenatural. Encuentra en él la explicación de tales entgmas: su origen último y su sobrevivencia. Tan poderosos factores espirituales han contribuído a una inesperada y asombrosa prolongación de la existencia más allá de sus límites reales que se manifiesta en la religión, la magia, el mito y el fuego. Por las vías de la inteligencia y de la emoción se ha creado ese otro mundo en que el hombre se apoya para ltbrarse de la angustia de su impotencia.

Las actividades de tipo religioso o mágico se dirigen a asegurar la eficacia de la técnica o la de la moral, el derecho y la política, creyendo en la intervención de seres o fuerzas más po. 
derosas que el hombre. Es este convencimiento de la intervención extra-real de entes superiores en los procesos de la vida ordinaria que pone en vigencia un sistema ritual o litúrgico, lado a lado do procedimientos técricos que no son considerados eficaces $\sin \alpha$ quel complemento. Todovía con moyor potencia actúa lo sobrenatural en los momentos difíciles para el hombre, cuando se ve amenazado por cataclismos, enfermedades, desgracias $y$ hechos infaustos en general y, por encima de todos ellos, la tremenda realidad de la muerte. No sin razón se ha atribuído al temor de esa realidad el origen de la religión. Como un sustitutivo de evidente trascendencia la cultura encontró la idea de la nueva vida después de la muerte o la supervivencia en condiciones tales que el $x$ vencida la angustia de morir ante la esperanza de una vida eterna.

En el balance de las actividades del hombre pesa, pues, mucho lo mágico-religioso y es imprescindible su estudio con mayor - igual interés que el dispensado a otros órdenes.

Sin embargo, prisionero el hombre dentro de lo real todo lo que inventa en relación con lo sobrenatural lo hace por los mismos medios con que traia las cosas que tiene a su alcance y al emplearlos magnifica la cotidiano y al mismo tiempo corporiza lo irreal. Su tratamiento con los dioses y los espíritus es similar al que emplea con los demás hombres da orcción. la ofrenda y el sacrificio para atraer la simpatía de los seres sobrenaturales se basan en la misma detitua del pleitesía, sûplicary Yutego a los seres humanos poderosos. De esta manera dos mundos real y sobrenatural se compenetran.

Cuando el hombre se empeña en comunicarse con los seres sobrenaturales usa de un lenguaje especial, de una expresión más depurada como en el caso de la poesía religiosa o de la música del mismo carácter, y para hacer visibles a los seres extrarreales que ha: creado se vale también de formas exquisitas tomadas de la naturaleza, sublimándolas. Así aparece el arte.

Al desarrollar su inteligencia en el doble sentido de captación de lo irreal y de lo real llega un momento en que intenta dominar el panorama entero hasta alcamzar una concepción de la totalìdad y dentro de ella fija su posición. Estamos en presencia de la filosofía.

Todo este juego de pensamientos y actividades se desenvuelve no sólo dentro de la conclencia individual sino en el seno mis. mo de la socledad contribuyendo a su formación y desarrollo no 
sólo los hombrss que viven en un momento dado $\mathrm{y}$ en un especio circunscrito sino de las generaciones que han ido dejando su herencia a través de los siglos y las gentes que integran otros grupos sociales. De este modo la cultura no se limita ni en el espacio ni en ei tiempo; pero contradictoriamente adquiere personalidad inconfundible sólo a combio de limitaciones espaciales y temporales : de ahí que el descubrimiento de una cultura se produce como si se dijera de un sólo golpe de vista. Tiene una configuración y un ethos. El grupo parece haberse conformado en el instante en que se le observa y presenta una organización inconfundible.

De análoga manera la existencia limitada del hombre, de cada hombre, en realidad no es toda la existencia que analiza el antropólogo; porque la cadena es ininterrumpida. La historia de la cultura es la llamada a poner en claro esta superexistencla, reconocténdola a lo largo del tlempo.

La historia en general responde a la necesidad humana de no detenerse en el hoy sino de ir en el sentido retrospectivo hasta las fuentes mismas del origen de la especle: el abolengo, la tradición, la genealogía responden a la misma necesidad. Las sociedades se vanaglorian de su pasado, hacen consistir su prestiglo en su mayor antigüedad. Ninguna quiere aparecer como recién nacida. La arqueología descubre en la profundídad de la tierra los testimonlos de esa antigüedod:

El estudio de una cultura debe(ser puesorealizado de dos maneras complementarias que pueden compararse a la fotogralía y a la cinematografia, es decir, la sociedad sorprendida en un momento dado y la sociedad moviéndose a lo largo del tiempo. Su estudio también comprende dos direcciones: una vertical, que se dirige hacia la profundidad y otra horizontal que se orlenta hacia la extensión; por la primera, se trata de descubrir todos los ante cedentes hasta llegar a la primera presencia del hombre; por la segunda, se pretende comprobar la irradiaclón en el más vasto espacto.

Condición esencial de la coexistencla es la posibilidad de co. municarse entre los que coexisten, y entre todos los seres orgánicos es sólo el hombre quien posee un sistema muy vasto de inter. comunicaciones, que llamamos lenguale.

A pesar del privilegio de ser el hombre la única especie animal que es sujeto de cultura, no ha alcanzado a hacer orgánica su trasmisión, requiriendo un constante entrenamiento la adquisi- 
ción y empleo del aparato cultural, que sólo se logra por medio de lo que entendemos como educación, en su mós amplio sentido.

El poder de la cultura es, sin embargo, tan grande que las funciones orgánicas y las conformaciones humanas naturales sufren su impacto, modificándolas muchas veces sustantivamente. El hombre, puede decirse, está enteramente interceptado por la cultura, de tal suerte que cún el paisaje es visto a través de la lente de la cultura a que se pertenece.

El mundo cultural engloba y trata de cubrir enteramente al mundo físico y al sobrenatural, pudiendo ofirmarse que éste último es una mera creación de aguél.

Por todo lo expuesto, se ve con claridad que la más limitada investigación social exige un conocimiento de estas ideas básicas. En el grupo social más simple encontramos implícita la compleiidad del macrocosmos cultural.

\section{BASES PARA UN ESTUDIO DE INTEGRACION REGIONAL}

Conviene ante todo determinar claramente lo que se entlende por una región. La primero acepción es de carácter geográfico: región es un cierto espacio identificable por su unidad, como un valle, una isla, una llanura. Se puede extender el sentido de la región, sin salir de lo geográfico a variosevalles dentro de una hoya principal, a varias islas, o archipiélagos. Todorvía más ampliamente a una porción de territorio que produce en forma similar (región del café, región de la caña de azúcar) u ofrece explotaciones anólogas: minas de carbón, yacimientos petrolíferos. Tal denominación también suele darse trecuentemente a una órea geográfica habitada por una población cultural y socialmente homogénea. Por último, región puede ser un conjunto de pueblos con unidad estructural y funcional.

El concepto de integración está relacionado siempre con el hombre y con la sociedad humana. La integración regional se refiere, por lo tanto, a planes que persigan estructurar un conjunto die pueblos que ya tienen vínculos trodicionales que abonan su unidad, pero que no funcionan armónica, equilibradamente, por faltarles algunos medios de promoción de los elementos que yacen inactivos o por carecer de una nítida conciencia de sus caracteres comunes y de sus fines solidarios. Se necesita, pues, ante todo, esclarecer tal conciencia y despertar aquellas fuerzas sociales subsumidas. Mas, no basta con la integración regional, sino que es 
menester el detentdo estudio de las relaciones o vínculos que unen la región, así entenájda, con el todo, es decir con la unidad superior compuesta por la suma de todas las reglones llámense nación o federación.

Además de esta ligadura entre la parte y el todo, precisa examinar las otras ligaduras entre las partes constitutivas de la na. ción o sea entre las regiones y aquéllas que no deben omitirse relativas a la acción y reacción entre regiones do distintos países, cuya comunicación puede ser directa o por intermedio del Estado nacional.

La integración no sólo se realiza con elementos internos, sino también externos. La facilidad en las comunicaciones hace cada día más influyente lo que llega de fuerć

Como bases para un estudio de integración regional, habría que contemplar una serie de investigaciones antropológicas e históricas previas, aparle de una de tipo geográfico indispensable.

Julian Steward, en su valioso trabajo sobre "Teoría y práctica del estudio de las áreas", detalla lo que también él considera las bases de un estudio regional.

En países como Guatemala y Perú con una rica y larga historia precolombina, se impone la investigación arqueológica para establecer los hitos del desarrollo cultural desde los más lejanos tiempos. Felizmentel la ofencla arqueológlea va adquiriendo consistencia cada, yez mayore die establecen oronologías casi exactó, que antes era casi impostble conseguir para aquelios vlejos pueblos ágrafos o con un sistema de escritura no descifrable aún. Una reconstrucción de las culturas onterlores a Colón debiera emprenderse, si no en toda su trayectoria, por lo menos en ei instante histórico en el que entran en contacto con los europeos.

Ia historia con fechas comlenza con este contacto y es desde entonces menos difícil situar los hechos a través de los últimos cuatro siglos. De esta historia conviene al estudio regional separar cuanto se refiere a la introducción de la nueva cultura y a la gran suma de cambios openados en todos los órdenes de la vida individual y colectiva, con sustitución o modificaclón de los patrones antiguos. Es de extraordinarlo interés la historia cultural de México, Guatemala, Ecuador, Perú y Bolivia en lo que toca al problema de hibridación que representa esta marcha conjunta de dos culturas tan disímiles como la autóctona amerlcana y la española. La investígación antropológica debe comprender el estudio total de la cultura de la zona que se trata do integrar en el momento 
presente, relacionándolo con el trabajo de arqueólogos e historiadores, para establecer la continuidad. La cooperación interdisciplinaria es de todo punto esencial así como el trabajo en equipo. La multivisión de todos los aspectos de la vida de una colectividad no se alcanza por un solo hombre ni desde un solo punto de observación. La concurrencia de gentes adiestradas en el conocimiento de persona, cultura, sociedad y medio físico resulta plenamente eficaz, pero a condición de coordinar sus investigacionss por el sometimiento a un plan común de trabajo y procedimientos controlables día a día.

Naturalmente, que un programa de integración regional, tratándose de Guatemala o del Perú, no ofrece la complejidad enorme de un estudio similar en grandes países como Estados Unidios, Ru. sta o Inglaterra.

Por esta causa, es factible la investigación interdisciplinaria. Para emprenderla es condición previa determinar con la mayor exactitud posible el área por estudiar, haclendo que concurran a tal fin los esfuerzos de geógrafos y antropólogos, oyudados de los demás especialistas en ciencias sociales y naturales. Las nuevas aportaciones de la etnobiología confluyen hacia este propósito. Una encuesta en Guatemala podría comenzar por la selección de una de las regiones en la que aporeciera mós nítidamente la unidad que se busca, fanto desde elpunto devista geográflco como desde el socio-cultural. Escogida la región el estudio conjunto iría determinando sus limites, su configuracion.

Ese estudio iría precisando cada vez con mayor objetividad el sujeto de la integración.

La entidad así individualizada aparecería con definidos contornos a trarvés del tiempo, podría ser reconocible en la bistoria y se lograría determinar los cambios operados, así como en el prcceso en marcha, con posibilidades de prever su futuro.

Ninguna investigación parcial (económica, política, jurídica o religiosa) es capaz de reconstituir el todo de una cultura, es decir, la vida de una sociedad desde sus múltiples aspectos. Es tan inextricable la maraña de relaciones humanas que sólo un esfuerzo de comprensión y de atento estudio puede conseguir el examen de la interdependencia de todos los órdenes de actividad cultural y la manera cómo se producen los cambios, los desajustes, los conflictos y su soluciones, dentro del órea escogida.

Se llega, pues, a la conclusión de que tado estudio de integración regional debe comprender la suma de investigaciones acon- 
sejada por la Antropología Cultural, en sus dos fases capitales: etnografía o descripción y etnología o interpretación.

Este estudio no debe detenerse en la región aislada, sino englobar cuanto atañe a la forma de inserción de ese segmento en el organismo más vasto de la sociedad nacional. El juego de acciones y reacciones entre el todo $y$ las partes, como lo observa Steward, ha sido frecuentemente olvidado en las monografías regionales o comunales. No es ocioso repetir que la investigación social es trunca cuando se limita al hoy, cuando prescinde de la historia y también cuando olvida que todo trabajo de ese género debe tener utilidad inmediata, o sea servir de fundamento para toda planificación. La antropología aplicada entra en funciones $y$ ofrece a pueblos desarrollados o semi-desarrollados el derrotero menos inseguro para políticos, economistas, juristas $y$ demás científicos encargados de la praxis de una sociedad.

\section{"LA CULTURA EMERGENTE"}

El distinguido antropólogo Mr. John Gillin define la cultura nacional emergente de Guatemala como "la que encierra y expresa las aspiraciones de la mayoría de la población políticamente activa del país, y representa los deseos $y$ captitudes de los guatemaltecos ante el mundo".

Dicha definición es aplicable a pueblos similares al guatemalteco, como son el mexicano, el peruano, el ecuatoriano o el boliviano. Podríase, pues, hablar de una cultura emergente indohispánica, teniendo en cuenta el fuerte sedimento indígena de cada uno de dichos pueblos, y la común herencia española.

Gtllin habla de la tendencia aparecida, después de la segunda guerra, entre las clases dirigentes, en el sentido de conducir a su colectividad hacia nuestro siglo. En efecto, en Guatemala $y$ en otras naciones del mundo latinoamericano, existe ese cardinal propósito de acelerar la marcha, quemando etapas, hasta alcanzar el mismo nivel de las más "adelantadas".

Cuando, en el caso de Guatemala, Gillin examina el sector de población en que aparece tal tendencia, descubre que dicho país no tiene una cultura nacional uniforme y homogénea (como tampoco Perú, Ecuador y Bolivia), pues existe un considerable porcentaje de indígenas que no pueden ser considenados como plenamente participantes de la cultura nacional. Esa no participa- 
ción se debe no tan sólo a su analfabetismo, como parece insinuarlo Gillin, sino al hecho más significativo de que su estilo de vida es muy distinto al de los grupos no-indígenas, incluso por el idioma.

Introduce Gillin un concepto muy interesante cuando nos habla de la "masa media" en sustitución de la clase media. Dice textualmente: "La masa media de Guatemala comprende a personas escalonadas a lo largo de todo el camino que va desde maestros de escuela en provincias y tenderos del campo hasta oficiales del ejército regular y miembros prominentes del gobierno".

Reconoce Gillin tres rasgos peculiares de esta masa que la colocan por encima de las clases bajas : $1^{0}$ el menosprecio por el trabajo manual, $2^{\circ}$ su alfabetismo ( $y$ habría que añadir su castellanización) y $3^{\circ}$ su sentido de la "decencia", revelado en la indumentaria, la habitación y otros signos exteriores.

Aunque el reconocimiento del status es muy variable; puede lograrse en el campo, mas no en la sociedad urbana. Igual variabilidad se presenta desde el punto de vista económico y aún desde el de la educación.

Gillin hace ver que la llamada-masa media es también social y funcionalmente distinta de las clases altas, a las que no puede igualar, ni por el abolengo, ni por la riqueza; sin embargo, dicha masa presumerpeseerceilaldanzarnelemismo prestigio de aquéllas.

Si por un lado, la masa media carece de tradición y de poder económico y, por otro, posee condiciones de accesibilidad a las nuevas posibilidades que le ofrece el mundo contemporáneo (técnica, educación, promoción económica), no hay ninguna duda que este grupo social se halla en buenas condiciones para constituir el elemento dinámico de la cultura emergente.

Cuando Gillin analiza la cultura guatemalteca encuentra en ella, como puede hacerlo en el Perú, por ejemplo: ciertos complefos dominantes de valores tradicionales que la masa medio comparte, a pesar de la heterogeneidad de sus componentes.

Enumera Gillin dichos complejos en la siguiente forma :

1 -El personalismo,

2 - El alto valor atribuído a la familia $\mathrm{y}$ al parentesco,

3 - Lo trascendental (o espiritual?),

4 - Tipo especial de valor de las cosas tangibles, 
5-Idea de orden estratificado en la sociedad y el universo,

6 - Alto valor de las emociones y estados internos,

7 - Cierto fatalismo.

Estos complejos integrarían la base sobre la que se está formando la cultura moderna. De ella emerge.

Gillin, antes de pasar adelante, explica lo que entiende por complejo de valores dominantes o reclores dentro de una cultura. Dice que él provee de un patrón de percepción o un modo de ver el mundo y las gentes, dota de una serie de creeencias explicativas para racionalizar la existencia, señala uno o varias metas hacia las cuales debe dirigirse el esfuerzo humano, ofrece ciertos patrones insirumentales o modos de acción para alcanzar djchas metas; igualmente determinados medios de expresión o símbolos; finalmente, Gillin manilesta que el "corazón del complejo de valores consiste en un juego o sistema de premisas de evaluación, explícitas o implícitas, por medio de las cuales se tasan los restantes componentes del mismo, de acuerdo con una escala de impartancia, deseabilidad y bondad". Añade Gillin que la práctica $y$ entrenamiento en el empleo de dicho complejo, genera cierta constelación de emociones e impulsos psicológicos reconocidos como apropiados.

Examina Gillin cada uno de los elementos enumerados y hace especial considetación aceric@ del/concepto de "alma", entre los hispanoamericanos, que no concuerda con el expresado con las palabras SOUL o EGO. Gira alrededor de tal idea el comportamiento y de ella derivan el sentido de "respeto" y de "dignidad personal". Iuzga Gillin que el origen de tales conceptos hay que buscarlo, tanto en el catolicismo, como en la tradición indígena.

Evidentemente que el carácter esencial, inseparable de la persona humana, que tiene el ánima, alma o espiritu, según la concepción citada, arranca de muy lejanas fuentes; pero, precisa establecer con mayor hondura lo diferencial. ¿Es realmente tan distinto el sentldo de esas palabras entre las gentes de culturas separadas? Hay un substratum humano universal que se necesitaria analizar previamente. Conviene, pues, alguna reserva en este punto.

El personalismo, muestra visible de tal idea, es una nota que aparece con frecuencia en la vida contemporónea de estos países, sabre todo en su historia política con la figura del caudillo; mas, el problema del condillaje no se soluciona con un mero exa- 
men psicológico, sino que abarca el vasto campo de la sociologíc: y de la antropología cultural.

La influencia personalista se ve a cada rato en los países latincamericanos, en que juegan papel principal las amistades $Y$ los compadrazgos, aun para la resolución de trascendentales asunlos del Estado. Como una concreción aún más palpable, se ve la importancia que tiene el parentesco, no sólo en lo social, sino en lo político en la forma de tendencias nepóticas poderosas.

Tiene razón Gillin cuando afirma que el parentesco ceremonial o compadrazgo posee el más alto valor, principalmente en las clases bajas, cuando esa relación se contrae con gentes de la clase al ta o masa media. Es una relación protectiva muy buscada.

Son exactas las observaciones de Gillin contenidas en el siguiente párrafo: "La importancia atribuída a los lazos personales $\mathrm{y}$ del parentesco, se orienta hacia una vida social ferviente y una forma de satisfacción del yo, que resulta imposible en el anoni. mato e impersonalidad de ciertas culturas modernas".

Respecto de la espiritualidad en los latinoamericanos, precisa distinguir entre aquel fondo tradicional a que hace referencia Gillin y la realidad actual futertemente influida por el afón de "hacer plata". El desajuste marca serio desequilibrio en el orden moral. El paso acelerado de un estado económico de gran pobreza on la inmensa mayoría acotre en que grupos cada vez mayores alcanzan un cierto nivel de riqueza nunca alcanzado, está determinando la vígencia de lo que se llama "espiritu práctíco", o sentido realista, para enmascarar un sórdido deseo de enriquecimiento rópido, por cualquier medio, sin escrúpulo alguno.

Ya sea por un desarrollo acelerado, pero normal, de la vida económica o como resultado de políticas inflacionistas, no hay duda que se cuenta con un campo más vasio de negocios y una mayor abundancia de dinero, que hacen posible un cambio pronto en el status $y$ ofrecen la ilusión de "hacerse millonarios" en poco tiempo. A la activtdad mercantil o industrial se agrega otro género de prácticas y objetivos que ya no proceden del negocio sino del juego: la Lotería, la Polla (en el Perú), la quina o el "bicho" (en el Brasil).

La deserción del campesino convertido en proletario urbano significa - por lo menos en Perú y Bolivia- una sensible pérdida de valores espirituales sin sustitución por otros valores de la misma naturaleza. El indio que cree en sus dioses tutelares antíguos o en los santos patronos católicos, al transformarse en poblador de 
la ciudad, abandona no sólo sus prácticas sino incluso las creencias mismas.

Acerca de la idea de un orden estratificado y jerárquico en la sociedad y en el universo, Gillin hace la aguda observación de que en Guatemala, por su conformación geográfica, todas las cosas y lugares están situados arriba o abajo. Lo mismo puede decirse de los países andinos, en que los hombres y las cosas ocupan su lugar alto o bajo. Dice Gillin que tal conceptc jerárquico contradice todo principio de igualdad. Cada ser humano es único.

Estima Gillin, que es una ventaja para Guatemala que su estructura social no sea tan rígida, lo que facilita el incremento de la masa media, a diferencia de otros países como el Perú en que pesa aún la tradición jerárquica virreinal. Conviene aclarar que en estos últimos veinte años dicha tradición ha enirado en un rápido proceso de liquidación ante el avance de la economía : los nuevos ricos están sustituyendo a las rancias familias de blasón hispónico.

El fenómeno que se presenta en el Perú es que la clase alta, la plutocracia, no ha alcanzado aún a ponerse a tono con los nuevos tiempos. Su mentalidad retrasada impide que se produzcan los cambios indispensables para advenir a la era del industrialismo. La predicaión de Gilin de que Gúatemala producirá una flo. ración de bellas artes puede extenderse/a_Ecuador, Bolivia y Perú، donde no sólo el arte popular, cada vez más lozano y vigoroso, sino las artes "sabias" están dando frutos de gran caltdad. Este fenómeno del desarrollo artístico en períodos de tensión social es registrado en la historia de la cultura como algo cíclico.

El fatalismo a que se refiere Gillin no tiene el sentido árabe del "estar escrito"; es más bien una conformidad o resignación melancólica quo concuerdan con el quietismo de viejos pueblos de agricultores pacíficos.

Entre otros elementos que pudieran agregarse a los enumerados por Gillin, podríase citar la especie de maternalismo o supervivencia matronímica que se manifiesta en la clase que integran los indígenas $\mathrm{y}$ tiene cabida en la masa media. El papel de la mujer es de activa participación en la vida social y familiar como unidad económica de alto valor, como educadora, como jefe virtual del hogar. Pero, es cuún más profundo este materialismo: lo hallamos en el campo religioso, ya en tiempos precolombinos que en este aspecto se prolongan hasta hoy, ya en tiempos virrei- 
nales en que se introduce la nueva religión. Son las Madres seres venerados como creadoras y "dueñas" tanto de los seres humanos como de las cosas de la naturaleza. Mama Ocllo es la madre del Imperio Incaico (o Mama Huaco), Mama Sara es la madre del maíz, Mama Cocha es la madre de las aguas, Mama Pacha es la Tierra, Mama "Señora" es la matrona, jefe de una tamilia extendida, Mamacha Belén es la Virgen católica en el Cus$\mathrm{co}$, como lo son con el mismo carácter de prioridad la Virgen de Guadalupe en México o la Virgen de Copacabana en Sud-perú y Bolivia.

Hay una muy fuerte tendencia en las clases baja y media hacia este maternalismo que hace de la mujer y del principio femenino en general algo decisivo, sustantivo, en la vida del individuo $\mathrm{y}$ de la colectividad, en la naturaleza $\mathrm{y}$ en la historia.

Suscribimos las mismas afirmaciones de Gillin sobre el futuro de la cultura nacional emergente, sobre todo cuando dice: "Sobre la base de sus propias tradiciones culturales... (Guatemala) desarrollará una nueva cultura encarninada a afrontar los problemas que afectan a una nación del mundo moderno".

La ciencia $y$ la técnica contemporáneas deberán introducirse teniendo en seria cuenta las propias madalidades del pueblo que las recibe. Sólo así serán eficaces.

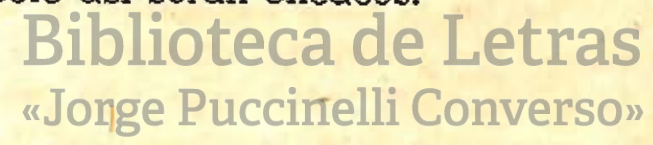

